\title{
The Search for "the Essence of Human Language" in Wittgenstein and Davidson
}

Forthcoming in Wittgenstein and Davidson on Thought and Action, Claudine Verheggen, ed., Cambridge University Press.

Jason Bridges

University of Chicago

June 2016

1. If we are looking for a narrative thread that ties together the kaleidoscopic ruminations of the first 137 sections of the "album" of "philosophical remarks" (PI 4) that is Philosophical Investigations, an attractive candidate is the philosopher's perennial quest to grasp "Das Wesen der menschlichen Sprache” $(\$ 1)$. All throughout these sections, Wittgenstein represents his diverse observations, examples and arguments as addressed to attempts to articulate language's "essence", either by serving as rejoinders to particular "pictures" of a supposed "essence", or as directly challenging the idea that there is such an "essence" to be grasped at all.

Let us briefly remind ourselves of the pervasiveness of this framing.

The Investigations begins with a passage from Augustine, about which Wittgenstein's first comment is that it "gives us a particular picture of the essence of human language" $(\$ 1)$. This "picture" is said to be the "roots" of a "philosophical concept of meaning" according to which "every word" has a "meaning" that is "the object for which it stands" (\$1-2). "Augustine’s conception of language", Wittgenstein writes, "surrounds the working of language with a haze which makes clear vision impossible" (\$\$4-5). The examination that follows of "primitive forms of language", such as the "language-game" of the builders and their assistants chronicled in $\$ 2$, proceeds from the hope that this examination will "disperse the fog" produced by Augustine's conception $(\$ 5)$. 
In $\$ 46$ we are offered a snippet of another classic text, the Theaetetus. The quoted passage posits "primary elements" that admit of no "determination" other than a "bare name". It concludes with the pronouncement that "the essence of speech is the combination of names" (\$46). Wittgenstein tells us that he will "apply the method of $\$ 2$ to the account in the Theaetetus" (\$48). His ensuing examination of various primitive "language-games" encourages us to recognize the relativity to interest and topic of our application of the concepts of "simple" and "complex", and to reflect on the implications of this fact for the nature of the understanding we can achieve by the "analysis" (\$\$60,64) of language into "simple" or “primary” elements.

In $\$ 65$, Wittgenstein suggests that the preceding discussion is likely to prompt an objection: "You take the easy way out! You talk about all sorts of language-games, but have nowhere said what the essence of a language-game, and hence of language, is” $(\$ 65)$. Wittgenstein does not regard this protest as trivial or beside the point. On the contrary, it raises "the great question that lies behind all these considerations" $(\$ 65)$. Moreover, the objection is partly correct: Wittgenstein has not tried to provide the kind of comprehension of language the protester is after. But that is not because he wants to take the easy way out; it is because language has no such "essence" to comprehend. Wittgenstein says that he will "try to explain this". In the sections that follow, he enlists the idea of "family resemblances" (\$67) in a bid to expose as misbegotten our hankering for the imagined form of understanding or insight into language with which we associate the rubric of "essence".

“These considerations", Wittgenstein now writes in $\$ 89$, "bring us to the problem: in what sense is logic something sublime?" The perception that "logic has a peculiar depth" (\$89), and our desire to plumb that depth, "finds expression in questions as to the essence of language, of propositions, of thought” (\$92). The appearance of profundity surrounding such 
questions is fueled by the perception that "the essence", whatever it may be, "is hidden from us" (\$92). We are subject to the "illusion that what is peculiar, profound, essential, in our investigation, resides in its trying to grasp the incomparable essence of language” (\$97). It helps in puncturing this illusion, Wittgenstein tells us, to appreciate the force of the observation that "if the words 'language', 'experience', 'world', have a use, it must be as humble a one as that of the words 'table', 'lamp', 'door”' (\$97). This in turn is an instance of a dialectical move that has application elsewhere in philosophy: "When philosophers use a word'knowledge', 'being', 'object', 'I', 'proposition', 'name'-and try to grasp the essence of the thing, one must always ask oneself: is the word ever actually used in this way in the language-game which is its original home?” (\$116)

2. The presence of the "essence" leitmotif is undeniable. But what are we to make of it? The philosophical topics explored in these sections, while interconnected, are wide-ranging and nuanced. (They are just as wide-ranging and nuanced here as they were when first taken up in the Tractatus, a text with which the early portion of the Investigations is obviously and explicitly in conversation.) If Wittgenstein has a reason for collecting the diverse bits of philosophy or proto-philosophy he discusses under one label, it is certainly not because they are addressed to some single, discrete philosophical question about linguistic meaning. The common element or theme indicated by the label, if there is one, must be a good deal more abstract.

I do think there is such an abstract commonality. What talk of "essence" signals throughout these sections, I suggest, is an aspiration on the part of Wittgenstein's interlocutor to achieve an insight into linguistic meaning that would be, in a sense I will shortly explain, external to our understanding of language in use. Whatever the details of the 
particular philosophical inquiry or debate within which a given picture or claim is entered, it counts as a picture of or claim about language's "essence" by embodying this aspiration—and so by depending for its point and sense upon the aspiration's intelligibility. Wittgenstein's primary critical message throughout this region of the text is that the prospect of such external insight into linguistic meaning is a fantasy.

The best way to get a grip on what an external understanding of linguistic meaning would be is to consider the kind of understanding of meaning with which it is meant to contrast. Our acquaintance with linguistic meaning, at least in the first instance, resides in our speaking a language. To speak a language is to have the capacity to use that language to say things. Exercises of such a capacity are intentional: if all goes well, you say what you intend to say. It follows that, in general, when you utter a sentence of a language you speak on some occasion, you know what you are saying. Insofar as others share your language, you will typically know what they are saying as well. The capacity to speak a language, then, entails a capacity to know what speakers of a language say when they utter sentences of that language. We might call what is here understood utterance-meaning; it is what is said or meant by a particular use of the language.

Now, while you are in general free to say whatever you like in a natural language you speak, you are not free to choose whatever expressions you like to say it. You cannot, speaking English, utter, "This vest is an odd shade of fuchsia," and thereby say that you're eligible to vote in Illinois. Particular English words, when conjoined together into particular sentences, can be used in particular circumstances to say particular things. A fluent speaker or writer of English will have a good sense of what is and is not thus possible in the language as it stands; a creative speaker or writer will point the way to new possibilities ramifying out from the old. That words in a natural language have concrete possibilities for, and concrete limitations 
upon, what they may be used to express; that these possibilities and limitations are in general fixed independently of any given uses of these words; and that it is part of the competence of a speaker of a language to have a firm grasp of these possibilities and limitations - all of this together justifies our distinguishing a second kind of meaning associated with language. This is expression-meaning, a property or character that expressions in a natural language possess independently of particular instances of their use.

The existence of two related forms of linguistic meaning, utterance-meaning and expression-meaning, raises the question of their relative priority. The answer is that there is dependence in both directions. On the one hand, it is in part in virtue of what expressions mean, independently of our particular uses of them, that we may use them to say the things that we do. There is thus a clear sense in which meanings of expressions precede and help provide for the meaning of their uses, for what speakers say or mean in using them on given occasions. On the other hand, our reflections to this point suggest that a speaker's understanding of what a word means is ultimately a matter of her understanding of what the word is, and can be, used to say. We were motivated to introduce the idea of the understanding of expression-meaning from consideration of what a person who can speak a language must know. And the capacity to speak a language is, of course, a capacity to use a language. More specifically, it is the capacity to use a language to say what one intends to say. So far as this capacity is concerned, it is use, and the understanding of use, that is fundamental. ${ }^{1}$

This thought is reinforced by attention to what is at stake in questions about our understanding of the meanings of particular words. When asked to explain the meaning of a

\footnotetext{
${ }^{1}$ C.f., Cavell on Wittgenstein's talk of meaning as use: " 'The meaning is the use' calls attention to the fact that what an expression means is a function of what it is used to mean or to say on specific occasions by human beings" (Cavell, 1999, p.206)
} 
given expression, what we say or do in response aims to make clear to our audience what a person who uses this expression would be speaking of, or talking about, or otherwise meaning, when she uses the expression. It is no accident that students tested on vocabulary are asked to "use the word in a sentence." The whole point of the exercise is to expand their boundaries of usage and comprehension of usage.

To reiterate: that we recognize any such phenomenon as linguistic meaning at all stems from our exercise of our capacity to speak a language - to use it to say things — and thus to understand such uses. It is in exercising that capacity that we find application for the concept of linguistic meaning, both with regard to uses of expressions and to the expressions themselves. The "home" $(\$ 116)$ of this concept lies in these exercises: it captures what we know about words and utterances when we bring this capacity to bear upon them.

At any rate, this is the primary, or initial, home of the concept. But need it be its sole home? The capacity to speak a language is itself something about which we may talk and think. It is a potential object of reflection. In particular, given the centrality of language to human life, and given its obvious connections with thought, knowledge, action and other important categories, it would seem an eminently fertile subject for philosophical inquiry. It's obvious that consideration of meaning will factor prominently into any such inquiries. And as we undertake such inquiries, the perception can easily arise that there is a need for, and a prospect of achieving, a second home for the concept of linguistic meaning. Or, to vary the figure, we may find ourselves thinking we require, and can have, a new perspective on the phenomenon of linguistic meaning, a perspective additional to that constituted by our exercise of the capacity to understand, in languages we speak, what people say and what words mean. To achieve such a perspective would be to find a way of recognizing and thinking about the meaningfulness of expressions and their uses that does not consist in our viewing those 
expressions and uses in the way that we do when we bring to bear upon them our capacity to speak and understand a language. The insights about meaning thus obtained would be in this sense external to our understanding of language in use. ${ }^{2}$

Of course, it is possible to recognize an expression or use of language as meaningful without understanding what it means. I know that words and utterances of Polish are meaningful, and I know this without exercising a capacity to speak Polish, for I have no such capacity. But that does not mean that I have a perspective on the meanings of Polish words and utterances that is external in the desired sense. My recognition of the meaningfulness of Polish words and utterances lies in my knowledge that there are people who speak Polish, and so that for these people the utterances and expressions of Polish have the same life that utterances and expressions of English have for me. There is nothing in this recognition to take me beyond what I know of linguistic meaning in possessing and exercising a capacity to speak a language. An external perspective must be a source of positive insights about meaningabout what it is, or about what makes or constitutes or provides for it - that does take me beyond such knowledge.

In philosophical reflection upon linguistic meaning, we may arrive at conclusions or observations that we were not in a position to formulate and recognize as correct in advance of this reflection. For example, we may uncover linkages between the concept of meaning and other fundamental concepts of human life and thought, such as that of truth, belief, intention and so on. If we can bring these linkages to light and find accurate and productive ways to characterize and discuss them, this will be an intellectual achievement. The fruits of this achievement may fairly be regarded as new insight into, or new knowledge about, meaning and language. But the newness of the insights will not suffice to show that we have achieved

${ }^{2}$ C.f., Stroud 2011, on Wittgenstein on our desire to get "outside language". 
an external perspective on meaning. Whether we have done so will depend upon whether recognition of these linkages puts us in a position to identify or explain or account for meaning in a way distinct from the grasp of meaning at work in exercises of our capacity to speak and understand language. It is arguable that many philosophers, historically, have been interested in these linkages precisely in virtue of the hope, explicit or inchoate, that they will show the way toward such a position. But in itself, the sheer prospect of identifying the linkages does not show that such a position is attainable. Indeed, it might be taken to cut the other way: it might be taken to suggest that not only the concept of linguistic meaning, but those of truth, belief, intention and the rest have as their home a set of interlocked capacities for thinking about the human being within which the capacity to speak and understand language is an essential and irreducible part.

What, then, would be involved in genuinely occupying an external perspective on linguistic meaning? There are many ways we might try to convince ourselves we have found the materials to achieve such a perspective. But what any such attempt must involve is an effort to impose upon linguistic meaning conceptual templates that are drawn from somewhere other than the forms of thought about meaning in which we engage when we exercise our capacity to speak and understand a language.

Consider, by analogy, the scientific treatment of a 'natural kind' concept such as that of water. It is no part of our ordinary concept of water that water has a certain chemical composition. One can perfectly well talk and think about water, and understand others' ordinary thought and talk about water, without knowing anything about its treatment in chemistry. The now-familiar identity claim, 'water is $\mathrm{H}_{2} \mathrm{O}$ '- not to mention the more accurate (I am told), 'Pure water is a mixture of ions composed of hydrogen and oxygen atoms that average out two to one'-embodies an alternative perspective upon water, a perspective that is 
external to the recognitional-cum-practical capacities constituting our possession of the ordinary concept. That our ordinary concept of water is a 'natural-kind' concept arguably provides for the intelligibility of these macrophysical/microphysical identity claims. But the material that fills out these claims - that furnishes our accounts of water's 'real essence'-is not built into our ordinary concept or into any knowledge or capacity that concept might plausibly be thought to implicate.

Some naturalistically-minded contemporary philosophers appear to think of linguistic meaning as a 'natural kind' possessing a scientifically-discoverable 'real essence'. ${ }^{3}$ But that is certainly not so of all, perhaps even of any, of the interlocutors whom Wittgenstein engages. The point of the analogy is more abstract. What Wittgenstein is concerned to root out, in our philosophical reflections on linguistic meaning, is our inclination to seek insight into the ground or nature of meaning by recasting it in terms of models, pictures or structures that are not native to the forms of thought about meaning in which we engage when we exercise our capacity to speak and understand a language. A range of perceived philosophical puzzlements may fuel this inclination. But whatever their motivation, our efforts to satisfy the inclination, Wittgenstein will argue, are bound to yield only confusion.

3. It is a measure of how fundamental - we might say, of how primitive - is the level at which this mode of criticism operates that Wittgenstein sees a fateful step in the wrong direction simply in our attaching explanatory or analytic significance to the thought that there are meanings. As soon as we think to posit meanings — or 'propositions', or 'thoughts' —as distinctive elements, items or objects whose presence in a scene of language use somehow helps explain or account for the meaningful character of that use, we have embarked on the

\footnotetext{
${ }^{3}$ See, e.g., many of the essays in Millikan 1993.
} 
search for an external perspective on meaning. For the vision of meanings-as-special-objects is not a deliverance of the exercise of our capacity to speak and understand a language. On the contrary: from the perspective of that capacity, it is an excrescence.

This crucial claim is made in various places, but it is given special emphasis in the initial sections of the Big Typescript (sections which, in that text, precede and set the stage for the discussion of Augustine that Wittgenstein will later choose to begin the Investigations). Consider, for example, the following remark: “The question, 'What do you mean?' is answered by 'I mean p', and not 'I mean what I mean by “p”' (BT 3). That is to say, we do not clear up a question about what we mean by drawing attention to a "meaning" associated with our use of a sentence, conceived as some kind of item that constitutes 'what we mean' by that sentence. Rather, we just use a sentence to say what we mean.

The text goes on:

If one always expresses oneself in a system of language and so uses only propositions of this system to explain what a proposition means, then in the end meaning drops out of language completely, and thus out of consideration; what remains is language, the only thing we can consider. (BT 3)

The point here is not that the languages we speak are in fact meaningless systems of signs. The point is that we do not need to "consider" any items additional to the sentences (here translated "propositions") we use in order to register the meaningfulness of these sentences and uses. Our appreciation of their meaningfulness stems not from our having in view any further such items, but simply from the fact that our relationship to these sentences is one of our using those sentences to express ourselves, to speak.

And again: 
If I give someone an order then it is quite enough for me to give him signs. And I would never say: 'These are mere words, and I have to get behind them.'

"But I meant something when I said that!"-Fine, but how can we recover what it was? Surely only by his telling us.... You mean what you say (BT 4).

That there is an item "behind" the words we use determining what we mean by them is not a thought we have when we are exercising our capacity to give or understand orders, or to tell someone something or to grasp what someone has told us. It can seem fruitful, or necessary, only if we abstract from what we know of utterances in exercising our capacity to make and understand them, and then cast about for some alternative way of conceiving the now absent "meaning".

4. What philosophical puzzlement might motivate our search for an external account of meaning, and how, beyond the bare idea of object-hood, of the reification of meaning, might we then seek to put flesh on our account? As I have said, there are many different possible answers to be gleaned from the Investigations, and elsewhere in the later writings. Perhaps the simplest are to be found in the path of reflection mapped in the early pages of The Blue Book.

There we are said to be struck by the perception that linguistic signs, considered on their own, "seem dead" (BB 4). They are just "dashes on a bit of paper"—or if spoken, just noises. How could such inert bits of physical matter or physical events have the "life" that belongs to the meaningful? This worry can be pressed in terms of what is nowadays called the “normativity” of meaning. An item's meaning determines conditions of correct use and response. A command's meaning, for example, fixes what would count as correctly executing 
it. But how could a mere mark on a paper, or a mere noise, determine any particular condition on how it is to be understood or responded to? "If I give someone the order 'fetch me a red flower from that meadow', how is he to know what sort of flower to bring, as I have only given him a word?” (BB 3)

The answer to which we seem forced is that there must be something present on the scene additional to the mere word, something which accompanies the word and does the correctnessdetermining work that the word itself cannot. And so "we are tempted to suppose that the action of language consists of two parts" (BB 3). On the one hand, there is the "inorganic part": "the handling of signs". This part was obvious all along. But what we now take ourselves to have discovered is that there must be an "organic part" as well, a parallel track of events or processes that run alongside the "inorganic" dealings with words. These further events and processes cannot just be more manipulations of dead signs. Precisely not: they must be such as to constitute the "life" we have found to be absent from such manipulations. It will now seem irresistible to locate these processes in the "mind". For it seems open to conceive the "mind" as a "queer kind of medium", capable of sustaining "mental processes" that "can bring about effects that no material mechanism could" (BB 3).

Let us retrace these steps in light of the previous discussion. Our puzzlement was said to arise from our sense that the linguistic expressions with which we are confronted, being mere marks or sounds, are "dead". Of course, if these expressions belong to a language we speak, and we allow ourselves to bring to bear upon them our capacity to understand that language, then neither these expressions, nor their uses on particular occasions, will seem "dead". Exercising this capacity on Wittgenstein's use of the English sentence, "Fetch me a red flower from the meadow", his utterance will have for us the "life", precisely, of an order to fetch a red flower from the meadow. Our perception that the utterance is after all dead, then, must reflect 
a conviction that we are not allowed to just help ourselves to what we know about it when we exercise upon it our capacity to understand English speech. The capacity, we must be supposing, is not self-vindicating. What it purports to reveal about the words and utterances of our language stands in need of validation, or explanation, from elsewhere.

Our way of attempting an external validation is to postulate special processes occurring in "the mechanism of the mind" (BB 3) that provide the "life" absent from our handling of “dead” signs. The concepts of process and of mechanism pick out ontological categories more determinate than the bare idea of an object or item. So we already seem to have more substance to our externalized conception of meaning than was to be gleaned from the passages from the Big Typescript quoted above. Moreover, the idea of a mechanism might seem especially suited to our explanatory purposes. The very idea of a mechanism is of a system whose characteristic processes can be described in terms of multiple families of concepts. As Wittgenstein puts the point in $\$ 149$ in discussing the notion of a mental "apparatus", processes implemented in a mechanism or apparatus are susceptible to two forms of characterization: one in terms of what the mechanism does or effects, and one in terms of how the mechanism is “constructed". Described in terms of its effects, our posited processes are presumably to be characterized as processes that say, yield or constitute an understanding of Wittgenstein's utterance as ordering the procurement of a red flower. To grasp the aptness of such a description would be to understand Wittgenstein's order, and thus to rely upon the very capacity for which we are currently endeavoring to account. But in envisioning understanding as effected by a process in a "queer kind of medium", we are holding out hope for a different way of characterizing that supposed process, a characterization, as Wittgenstein puts it, in terms of the mechanism's construction. Such a characterization would not depend upon conceiving these processes as producers of meaning or understanding, but would rather 
exploit independently available characterizations of structures or configurations in the envisioned "queer medium".

In fact, we have no inkling, and can have no inkling, of how such structures or configurations are to be described. We know that they cannot be physical, for "no physical mechanism could behave in this way" (BB 5). And so we think of them instead as having an “occult character" (BB 5). But we can get no farther than this. Our attempt to give an external account of meaning and understanding in terms of the operations of the "mind" has ended in obscurity. Unfortunately, the felt pressure to find an external account of meaning may be strong enough that we do not recognize our failure for what it is. Instead, we may mistake its obscurity for profundity. ${ }^{4}$

5. Let us return at last to the Investigations. I have suggested that the interlocutor's claims and pictures count as attempts at articulating language's "essence", in the manner of which Wittgenstein is critical, in virtue of being offered as attempts to fill out an external perspective upon linguistic meaning. This proposal, as we will see, illuminates various features of Wittgenstein’s discussion.

On its face, however, the proposal may seem a non-starter. The "picture" of the "essence of human language” Wittgenstein discerns in the passage from Augustine casts naming, or reference, as that "essence". The concept of reference, unlike that of a process or a mechanism, is semantic. It is a concept of word meaning. And so the thought that words refer is not foreign, but native, to the kind of understanding or knowledge yielded by exercises of our capacity to speak a language. This raises the question of how reference could possibly be

\footnotetext{
${ }^{4}$ For more on Wittgenstein's treatment of his interlocutors' many appeals to the idea of a mental mechanism, see Bridges forthcoming.
} 
supposed by Wittgenstein's interlocutors to provide a plausible basis or starting point for an external treatment of linguistic meaning.

The key to an answer to this question lies in the observation that the concept of the reference of a word is semantic, not pragmatic. It is a concept of expression-meaning, not utterance-meaning. Earlier, I suggested the concept of utterance-meaning is prior to that of expression-meaning: that what a word means is ultimately to be understood as a matter of what it can, in conjunction with other words, be used to say. But this thought might be denied. Indeed, the distinction between the meaning of a word and what is meant by speakers in using a word might be taken to open the possibility that a word's reference, belonging as it does to the first sort of meaning, could be accessible to us independently of our access to meaning of the second sort. We may still grant that what a word means is necessarily linked with what it can be used to say. But we might hope to exploit this linkage in the other direction, building from an external treatment of reference to an external understanding of the whole of meaning in use.

Viewed in this light, the identification of reference as the "essence" of language is one application of a more general thought: that expression-meaning-be it understood referentially or otherwise- is the key to the development of an external treatment of linguistic meaning. I take it that this more general idea is indeed in Wittgenstein's sights. In $\$ 5$ he speaks of the confusion that surrounds "the general concept of the meaning [der Bedeutung] of a word", and there is no indication that he thinks the confusion arises only when we conceive meanings of words in terms of their naming of objects. This comment harkens back to remarks from Philosophical Grammar that are still more explicit on this point. There Wittgenstein writes, "The way Augustine describes the learning of language can show us the way of looking at language from which the concept of the meaning of words derives" (PG §20). And he 
expresses our enthrallment to that "concept" this way: "We say: the essential thing in a word is its meaning" (PG \$22). That is, the very idea that words have meanings may seem to us to point toward, to begin to delineate, some picture of the "essence" of language.

The strategy we are now envisioning depends upon the prospect of finding a second home for the concept of a word's possession of meaning, and of its possession of reference in particular. Such a home must be constructed from concepts, pictures, or claims whose application to words is not given within the understanding of expressions and utterances internal to our capacity to speak a language. What materials might be thought to be suitable?

There are several answers to this question suggested in Investigations $\$ \$ 1-137$. One possibility is to try to conceive reference or signification as constituted by operations in the mind. We might suppose, for example, that a word's referring to what it does is a matter of its being associated with a mental image of its referent (c.f., §6). If the hopelessness of that thought becomes clear to us, then we may seek recourse in the idea that the mind is able to forge referential connections between words and objects in virtue of its mysterious and unique powers. We adopt a "conception of naming as a process that is, so to speak, occult. Naming seems to be a strange connection of a word with an object... [W] e may indeed imagine naming to be some remarkable mental act, as it were the baptism of an object” (\$38). Taking this route, we are squarely back in the territory examined in the Blue Book. In the sections after $\$ 137$, similar ideas about understanding are considered in great detail.

Second, we may endeavor to cast referential relations as implemented by a set of linguistic practices that can be separated out from, and understood independently of, the rest of our use of language. The supposed discrete character of these special practices may even encourage the thought that they are not, strictly speaking, uses of language at all, but are instead preparatory to such uses. This is the suggestion of the interlocutor $\$ 27$ : "We name things and then we can 
talk about them: can refer to them in talk." If naming happens in advance of talking, then, it might seem, we should be able to recognize a word as naming something without relying on our understanding of its role in talk. We might offer as an analogy: we sharpen a stone and only then can use it to cut things. Its sharpness must not simply be a matter of its being used to cut, and must therefore be cognizable in abstraction from that use.

Wittgenstein's response to the interlocutor's suggestions shows that he would regard any such analogy as profoundly misconceived. A stone might be sharpened and never be used to cut anything. But a word names nothing except insofar as it is used: "Naming is so far not a move in the language-game-any more than putting a piece in its place on the board is a move in chess. We may say: nothing has so far been done, when a thing has been named. It has not even got a name except in the language-game” $(\$ 49)$. And that is because to say what a word names is to say something about what is meant by those who use it: "What is the relation between name and thing named? - Well, what is it? Look at language-game (2) or at another one: there you can see the sort of thing this relation consists in.” (\$37)

Third, we may try grasp referential relationships from outside our capacity to use and understand language by supposing that these relationships are to be identified by a special activity of "analysis" of language $(\$ 92)$. What is distinctive about this activity is that it is not just a matter of being explicit, or observant, or self-conscious, about patterns and structures discernible within what we know, or can come to recognize, in exercising our capacity to speak and understand a language. The envisioned activity is not in this sense a matter of examining "something that already lies open to view and that becomes surveyable by a rearrangement" (\$92). Rather, it is a matter of getting at what "lies beneath the surface". "The essence" that we are after "is hidden from us.” Digging for such an "essence” will require our going beyond, 
or beneath, what is already available to us as speakers. It will be to seek an external perspective.

Such a project is motivated by, and derives whatever sense it may have, from a perception that we in some way lack an adequate philosophical understanding of the status of language until we grasp its "hidden essence". We might attempt to indicate the place of the missing understanding by speaking of, for example, the need to grasp the "super-order" between the “super-concepts” of "language” and “world” (\$97). Reference, understood as a "bare”, unmediated confrontation between the words of a language and "the simple constituent parts of which reality is composed" $(\$ 47)$ might seem an essential tool in the articulation of such an order.

This third imagined strategy for achieving an external understanding of reference, and through reference an external understanding of meaning as such, is the most complex and difficult to understand. I will say no more about it except to register that is where the later Wittgenstein's treatment of the search for a hidden essence of language most explicitly confronts his earlier work:

My notion in the Tractatus Logico-Philosophicus was wrong: 1) because I wasn't clear about the sense of the words "a logical product is hidden in a sentence" (and suchlike), 2) because I too thought that logical analysis had to bring to light what was hidden (as chemical and physical analysis does). (PG 210)

6. Let us see now consider how the current reading illuminates Wittgenstein's initial moves in response to “Augustine's conception of language”, according to which "every word has a meaning" and "the meaning is the object for which the word stands". I am suggesting that the inclination to think that these words express the "essence" of language amounts to the 
intuition that the idea of a word's signifying an object can somehow be deployed to achieve external philosophical insight into linguistic meaning. At this very early stage of the Investigations, there is as yet little to no indication of what kind of philosophical puzzle or question might seem to motivate the search for such insight. This means that what is available at the outset for examination and criticism will be nothing more specific than the thought that the phenomenon of reference or signification is suited, in some way or another, to achieving some such insight of this kind. Thus whatever challenges are to be raised at this stage about the "philosophical concept of meaning" according to which signification or reference is language's essence, these challenges must engage this highly general commitment. And indeed, it is precisely this general thought that Wittgenstein seeks to cast doubt upon in the sections immediately following $\$ 1$. The main drift of these sections can be put succinctly as follows: we do not have and cannot have any grasp of what words refer to except in virtue of understanding what they can be used by speakers to say or otherwise mean.

Wittgenstein does not attempt to prove this denial — not surprisingly, given that it is difficult to see how anything approach a proof could be in the offing when we are jousting with such abstract, indeterminate explanatory hopes. But he does still try to give the denial teeth. How does he do so?

To begin with, he emphasizes the great diversity of uses that words possess. He says that someone who characterizes the learning of language as Augustine does must be "thinking primarily" of proper names and common nouns, and forgetting about other kinds of words $(\$ 1)$. He describes a linguistic interchange involving a shopkeeper that provides an initial illustration of that diversity $(\$ 1)$. Augustine, he then tells us, is like someone who offers a circumscribed account of games, to which we can reply, "You seem to be thinking of board games, but there are others" $(\$ 3)$. He deploys various images—of tools in a tool box $(\$ 11)$, of 
the controls in a locomotive $(\$ 12)$ - as metaphors for the variety of "absolutely unlike" $(\$ 10)$ uses to which we put words that may seem similar enough on their visible or audible faces.

Some readers have taken the point of these remarks to be that it is straightforwardly wrong to claim that every word signifies or names an object. ${ }^{5}$ This would seem to provide a direct refutation of the picture of "essence" given in $\$ 1$ : presumably, the naming or signifying of objects by words cannot be the "essence" of language if there are lots of words that don't name or signify objects.

But this reading is off-target. Wittgenstein never outright claims that there are words that cannot be understood to signify anything. And to take his point to be such a flat-footed denial goes again conspicuous features of the text. One of the words whose use in the example in $\$ 1$ is meant to cast doubt on "Augustine's conception" is the word "five". But in $\$ 10$, Wittgenstein grants that it can perfectly acceptable to say that numerals "signify numbers". If a word like "five" poses a problem for Augustine's conception, it is apparently not by serving as clear-cut counterexample to a well-defined universal generalization.

Furthermore, the attempt to portray naming or reference as the "essence" of language is, as I have suggested, just one possible way to try to make good on the thought that expressionmeaning is the "essence" of language. If this more general thought is to be exorcised through recognition of the failure of the picture of reference as language's "essence", then the morals of the latter's failure must be generalizable. It will not do, then, to rest much weight on the insistence that some expressions lack reference. For these expressions will nonetheless have meanings, even if not referential. What needs to be made plausible is that we have no way of understanding a word to possess a meaning except by conceiving of it as apt for use in saying this or that.

\footnotetext{
${ }^{5}$ Most famously, Baker and Hacker 2006, chapter 1.
} 
It is just this point that Wittgenstein's highlighting of the variety of uses of words aims to help us to see. Failing to register this variety, it might seem possible to think that our appreciation of the concept of the meaning of a word is a matter of our bringing to bear a common template upon all words, a template whose application in each case is understood and justified in more or less the same way. The abstract relational property of standing for an object might, indeed, seem perfectly suited to this role. This thought might suggest in turn that we can grasp how this template is to be applied to a word in advance of knowing very much about the particular uses to which the word is put. And this may, finally, pave the way for the thought that we can fairly readily substitute for our ordinary concept of expression meaning some surrogate constructed out of external materials. ${ }^{6}$ But once we acknowledge just how radically diverse and variegated these uses can be, the whole train of thought will fall apart. For the initiating idea of a common template will lose its plausibility. We will come to recognize how utterly dependent is our grasp of a word's "meaning" upon our appreciation of the particular ways in which we use the word. We will come to see the truth in the slogan that "the meaning of a word is its use in the language" (\$43; c.f., PG §23).

The intended import of Wittgenstein's appeal to the diversity of our use of words becomes clearer when we juxtapose that appeal with his treatment of a case in which no such variety is at issue. In $\$ 2$, Wittgenstein suggests that we "imagine a language for which the description given by Augustine is right" (\$2). This is the "primitive" language of the builders and their assistants. In this language there is only one kind of use for a word: each word in the language is a call for the assistant to bring a building stone of a particular shape. Does this

\footnotetext{
${ }^{6}$ A cousin to this line of thought can be found in contemporary work on "naturalized semantics", in which simple, streamlined structures of meaning are represented as the core of meaningfulness as such. The simplicity of the structures is precisely what seems to open the prospect of their reconstruction our of "naturalistic" relations such as those of nomological connection or evolutionary fitness. The work of Fred Dretske $(1981,1988)$ exemplifies this approach.
} 
mean that the language is a good fit for "Augustine's conception of language"? Evidently it does not:

Now what do the words of this language signify? - What is supposed to show what they signify, if not the kind of use they have? And we have already described that. So we are asking for the expression "This word signifies this" to be made a part of the description. In other words the description ought to take the form: "The word.... signifies....".

Of course, one can reduce the description of the use of the word "slab" to the statement that this word signifies this object. This will be done when, for example, it is merely a matter of removing the mistaken idea that the word "slab" refers to the shape of building-stone that we in fact call a "block"—-but the kind of 'referring' this is, that is to say the use of these words for the rest, is already known. $(\$ 10)$

Wittgenstein does not deny that the words in language-game $\$ 2$ signify objects. On the contrary, he grants that they do. His point is rather that what "shows what they signify" is "the kind of use" they have. Certainly these words refer to things, but "the kind of "referring"” in play is a function of "the rest of the use of the word". That is to say, we grasp what these words refer to only by understanding Wittgenstein's description of their use. Asking ourselves why we find it natural to say or think that "slab" in language $\$ 2$ refers to a certain shape of building stone, we can do no better than repeat, or summarize, the information provided in Wittgenstein's description.

Some philosophers who take themselves to be influenced by Wittgenstein promote a "use theory of meaning", according to which the meaning of a word or sentence derives from facts about its use that may be described without mention of what speakers mean in using it. ${ }^{7}$ If

\footnotetext{
${ }^{7}$ See especially Horwich 2005, chapter 2.
} 
Wittgenstein himself endorsed this view, we would expect him to provide descriptions of the use of language of the sort the view requires. But there is no sign anywhere that he is interested in doing so, and he certainly does not do so here. It is stipulated as part of the description of use in $\$ 2$ that the builders' words constitute a "language meant to serve for communication". In particular, we are told "B has to pass the stones, and that in the order in which A needs them". "For this purpose", Wittgenstein goes on, they "use a language" in which A calls out a word of the language, and B brings the stone "he has learnt to bring at such-and-such a call”. It is simply given in Wittgenstein's description, then, that the uses at issue are purposive speech acts. In particular, the description makes clear, as Wittgenstein says in $\$ 18$, that these speech acts are commands.

The upshot of the reflection on language-game $\$ 2$ undertaken in $\$ 10$ is not that a word's reference is fixed by facts about "use" that may be described in neutral, non-meaning-involving terms. Rather, it is that recognition of what a word refers to is available to us only via the exercise of a capacity to grasp characterizations of the use of language in which it is given that the speaker is saying and meaning particular things in using those words as she does. This implies that an appeal to reference cannot give us any insight into the "essence" of language of the sort we think we need.

It is this kind of point that is apt for generalization to expression of meaning as such. Take any putative semantic property you might think helpful to ascribe to words and other expressions. The claim will be that such ascriptions, insofar as they are intelligible to us, encapsulate patterns in how these expressions may be used to say things. 
7. The primordial level at which Wittgenstein's battles with "the search for the essence of human language" unfold gives his thought its distinctive power and reach. But it also presents an obstacle in bringing this thought to bear upon the work of actual philosophers.

Wittgenstein does not, in this region of his later work anymore than elsewhere, engage the characteristic results of philosophical theorizing: sophisticated theories, systems and arguments. His concern is not in where philosophical reflection ends up, but in where it begins, in the assumptions, ideas, pictures, impulses and confusions that lie at its roots. By the same token, he is not generally concerned to show that this or that philosophical thesis or theory is false, or that the arguments for them are unsound. It is far from clear that falseness and unsoundness are even in the cards. The worries cut deeper. They suggest that our attempts to articulate theses or construct arguments are controlled by intellectual aspirations that we do not really understand, indeed, that are not ultimately intelligible. But if that is so, then no claim or picture we put forward will have the significance we want it to have. Nor will they have any other significance, for what would give it to them if not our interests and intentions? So we are just spinning our wheels.

No philosopher is likely to accept this discouraging verdict on her activity. And given the great distance between the primitive pictures and notions upon which Wittgenstein focuses and the intricate subtleties of actual philosophical work, there will always seem room to deny that the work partakes of the impulses and tendencies Wittgenstein seeks to expose and critique. Moreover, the denial might be correct: not all philosophical reflection on language, after all, is automatically guilty of hankering after "essence". So how, in any given case, are we to tell?

I will close by brief consideration of an instructive test case: Donald Davidson. The case is instructive because while Davidson both shares many of Wittgenstein's convictions about 
language and explicitly disavows any reductionist or naturalistic aims in his account of meaning and thought, I think we can nonetheless detect in some of his core theses and arguments the signs of an interest in uncovering language's "essence". That even Davidson does not fully avoid the lure of the question for "essence" indicates the strength of its hold upon our philosophical imagination.

Davidson's points of overlap with Wittgenstein are significant. First, his thinking on language is organized around an insistence on the conceptual priority of utterance-meaning over expression-meaning. It is true that he does not conceive that primacy in quite the way that Wittgenstein does, largely because he does not share Wittgenstein's conception of use. Most notably, Davidson finds what is essential to the social dimension of language use in pairwise communicative interaction, disparaging the theoretical importance of shared natural languages, and doing so for reasons which, if valid, would equally discredit Wittgenstein's appeals to language games and practices as necessary contexts for meaning. ${ }^{8}$ But at the same time, Davidson also enriches our appreciation of the context required for meaningful language use. He reminds us that our capacity to ascribe meanings to a speaker's utterances is a component of our capacity to grasp the whole mise-en-scene of the speaker's rational engagement with the world. If we are to know what a speaker is saying, we must also grasp what she thinks and intends, and we cannot do that unless we can find rational intelligibility, and a firm grasp of reality as we understand it, in those thoughts and intentions. Among other valuable results, Davidson's emphasis on the interdependence of meaning and "the propositional attitudes" provides further grounds for rejecting a mechanistic treatment the mental.

\footnotetext{
${ }^{8}$ See, especially, Davidson 1986.
} 
Second, Davidson shares Wittgenstein’s distrust of hypostasizing talk of propositions, meanings, and other such items. He sees in it little explanatory power, and much opportunity for confusion. A major part of the motivation for his proposal to use a Tarski-style theory of truth as theory of meaning is to relegate explicit talk of meaning to the background.

How about the other side of the ledger? Where I think we can see traces in Davidson of an un-Wittgensteinian desire to find an external perspective on linguistic meaning is in the enormous importance he assigns to the conceptual possibility of "radical interpretation"-i.e., of the derivation of a comprehensive assignment of meaning, beliefs and desires to a speaker solely on the basis of knowledge of what sentences of her idiolect she "holds true". In principle, we can know that a person holds a sentence she utters to be true without knowing what she means by that sentence, and so correlatively without knowing what beliefs and desires she thereby expresses. Part of the burden of the famous essay, Davidson 1973, is to explain how we could exploit presumptions of charity and rationality to bootstrap knowledge of sentences held true into full-fledged knowledge of meaning, belief and desire. 17 years later, in Davidson 1990, the prospect of such a derivation is still front and center, with the required principles, assumptions and technical machinery spelled out with much greater care. In these essays and elsewhere, Davidson draws substantial and surprising philosophical conclusions from his account of the procedures of radical interpretation. But so far as I can see, he never provides a satisfactory explanation of why we should draw these conclusions, or indeed any philosophical conclusions, from the account.

One of Davidson's conclusions is that it is a necessary condition on being a speaker and thinker that one's utterances can in principle be subject to radical interpretation. But why should this be so? Suppose we were to discover some flaw in Davidson's radical-interpretive method, which exploits ideas from Ramsey's theory of subjective probability. Why should we 
be confident that the flaw could in principle be corrected? Davidson is careful to emphasize that he is not offering a reconstruction of how we actually do understand the speech of others. Why then, should we believe in, or care about, radical interpretation's conceptual or logical possibility? ${ }^{9}$

A second conclusion is that meaning is indeterminate. Davidson represents this indeterminacy as no less benign and unexceptional than the relativity of an object's numerical length to the units of measure: vary the unit, and you change the number. ${ }^{10}$ It is the interdependence of assignments of meanings and assignments of propositional attitudes that is here being analogized: vary the belief ascribed, say, and you must adjust your assignment of meaning accordingly. But what, then, is analogous to the side of the object that is measured? The answer must be the speaker's linguistic behavior. And if the analogy is to make sense, the behavior, in itself, must not be capable of deciding between different paired assignments of meanings and attitudes, anymore than an object's side can be such as to decide between descriptions of it as 12 inches long vs. 1 foot long. If we suppose that a person's behavior, in the relevant sense, is constituted by facts about what sentences she asserts or holds true, then this result is achieved. It seems evident that, primed by his reflections on radical interpretation, Davidson does conceive the speaker's behavior in this way. But why? Why not suppose that the proper conception of the behavior to which our ascriptions of attitudes and meaning are answerable is one according to which it is not merely given that a speaker asserts and holds true the sentence, say, "It's raining," but it is given as well that in uttering this sentence, she says, precisely, that it is raining?

\footnotetext{
9 Davidson's later work on 'triangulation' introduces material relevant to this question. For a criticism of that work, see Bridges 2006.

${ }^{10}$ Davidson 1998, p.317.
} 
These gaps in Davidson's arguments might be filled if we could find a reason for demanding that philosophy show how meaning somehow arises from, or is somehow grounded in, facts about which sentences a speaker asserts or holds true. One possible justification for this demand is that its satisfaction would be a step toward achieving externality. ${ }^{11}$ Is there anything else to be said for it?

\section{References}

Baker, G.P. and P.M.S. Baker. 2005. Wittgenstein: Understanding and Meaning. Wiley-Blackwell. Bridges, Jason. 2006. “Davidson’s Transcendental Externalism.” Philosophy and Phenomenological Research 73 (2): 290-315.

Bridges, Jason. Forthcoming. "Meaning and Understanding." In A Companion to Wittgenstein, eds. Hans-Johann Glock and John Hyman. Wiley-Blackwell.

Cavell, Stanley. 1999. The Claim of Reason. Cambridge: Harvard University Press.

Davidson, Donald. 1973. "Radical Interpretation.” In Davidson 1984.

Davidson, Donald. 1984. Inquiries into Truth and Interpretation. Oxford: Clarendon Press.

Davidson, Donald. 1986. “A Nice Derangement of Epitaphs.” In Davidson 2005.

Davidson, Donald. 1995. “The Structure and Content of Truth”. In Davidson 2001.

Davidson, Donald. 1998. "Replies to Rorty, Stroud, McDowell, and Pereda”. In Davidson 2005.

Davidson, Donald. 2001. Subjective, Intersubjective, Objective. Oxford: Clarendon Press.

Davidson, Donald. 2005. Truth, Language and History. Oxford: Clarendon Press.

Dretske, Fred. 1981. Knowledge and the Flow of Information. Cambridge: MIT Press.

Dretske, Fred. 1988. Explaining Behaviour. Cambridge: MIT Press.

Horwich, Paul. 2005. Reflections on Meaning. Clarendon Press.

11 This is in effect David Lewis's justification for taking an interest in the problem of radical interpretation. See Lewis 1974, p.110. 
Lewis, David. 1974. "Radical Interpretation”, in his Philosophical Papers, v.1, Oxford: Oxford University Press, 1983.

Millikan, Ruth-Garrett. 1993. White Queen Psychology and Other Essays. MIT Press.

Stroud, Barry. 2011. "Meaning and Understanding", In The Oxford Companion to Wittgenstein, eds. Oskari Kuusela and Marie McGinn. Oxford: Oxford University Press.

Wittgenstein, Ludwig. 1922. Tractatus Logico-Philosophicus. London: Routledge and Kegan Paul.

Wittgenstein, Ludwig. 1953. Philosophical Investigations. Oxford: Blackwell.

Wittgenstein, Ludwig. 1965. The Blue and Brown Books. Harper Torchbooks.

Wittgenstein, Ludwig. 1974. Philosophical Grammar. Oxford: Blackwell.

Wittgenstein, Ludwig. 2006. Big Transcript: TS 213. Oxford: Wiley-Blackwell. 